\title{
Synthesis of Epitaxial Metal Oxide Nanocrystals via a Phase Separation Approach
}

\author{
Kashinath A. Bogle, ${ }^{\dagger}$ Varatharajan Anbusathaiah, ${ }^{\dagger}$ Miryam Arredondo, ${ }^{\dagger}$ Jiunn-Yuan Lin, ${ }^{\ddagger}$ Ying-Hao Chu, ${ }^{\S}$ \\ Christopher O’Neill, John M. Gregg," Martin R. Castell, ${ }^{\perp}$ and Valanoor Nagarajan ${ }^{\dagger, *}$ \\ ${ }^{\dagger}$ School of Materials Science and Engineering, University of New South Wales, Sydney 2052, Australia, ${ }^{\ddagger}$ Institute of Physics and ${ }^{\S}$ Department of Materials Science and \\ Engineering, National Chiao Tung University, Hsinchu, 30010, Taiwan, "Center for Nanostructured Media, School of Mathematics and Physics, Queen's University Belfast, \\ Belfast BT7 1NN, North Ireland, United Kingdom, and ${ }^{\perp}$ Department of Materials, University of Oxford, Parks Road, Oxford OX1 3PH, United Kingdom
}

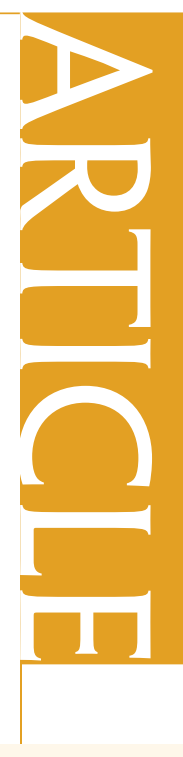

M agnetic spinel nanocrystals are an important class of functional oxides that possess interesting magnetic, magnetoresistive, and magnetooptical properties. ${ }^{1-6}$ These properties are a strong function of the shape, size, and crystallinity of the nanocrystals, and consequently, the ability to synthesize highdensity nanocrystals with controlled spacing, shape, and size has emerged as one of the most dominant themes. ${ }^{7-16}$ While a number of soft-chemistry routes to high-density magnetic nanocrystals have been reported, ${ }^{5,11,17-20}$ the generation of discrete magnetic nanocrystals on an underlying oxide substrate without the use of templates still remains a substantial challenge. The use of oxide substrates provides a pathway to explore the fundamental properties of these oxide nanostructures with strict control of different orientations, shape, and morphology, which may not be easily achieved by other methods.

In this report, we present a new and facile physical deposition method to fabricate free-standing high-density $\mathrm{Mn}_{3} \mathrm{O}_{4}$ magnetic spinel nanocrystals. Interest in this material is driven by not only magnetic but also novel electrochemical, ${ }^{21}$ biomedical, ${ }_{1}^{22-24}$ and catalytical properties. ${ }^{24-26}$ Additionally, the possibility to oxidize the high-density $\mathrm{Mn}_{3} \mathrm{O}_{4}$ spinel nanocrystal array under ex situ conditions to manganese dioxide $\left(\mathrm{MnO}_{2}\right)$ offers significant potential in battery applications. Here we demonstrate that under certain (high) temperature and relatively oxygen-rich conditions, pulsed laser deposition (PLD) of the $\mathrm{BiMnO}_{3}$ perovskite precursor can yield completely phase-separated constituent $\mathrm{Bi}_{2} \mathrm{O}_{3}$ and $\mathrm{Mn}_{3} \mathrm{O}_{4}$ phases. Subsequent cooling of the sample in high-
ABSTRACT Perovskite phase instability of $\mathrm{BiMnO}_{3}$ has been exploited to synthesize epitaxial metal oxide magnetic nanocrystals. Thin film processing conditions are tuned to promote the breakdown of the perovskite precursor into $\mathrm{Bi}_{2} \mathrm{O}_{3}$ matrix and magnetic manganese oxide islands. Subsequent cooling in vacuum ensures complete volatization of the $\mathrm{Bi}_{2} \mathrm{O}_{3}$, thus leaving behind an array of self-assembled magnetic $\mathrm{Mn}_{3} \mathrm{O}_{4}$ nanostructures. Both shape and size can be systematically controlled by the ambient oxygen environments and deposition time. As such, this approach can be extended to any other Bi-based complex ternary oxide system as it primarily hinges on the breakdown of parent $\mathrm{Bi}$-based precursor and subsequent $\mathrm{Bi}_{2} \mathrm{O}_{3}$ volatization.

KEYWORDS: epitaxial nanocrystals · pulse laser deposition - metal oxide · phase separation - volatization

vacuum conditions $\left(10^{-7}\right.$ Torr) results in complete volatization of the $\mathrm{Bi}_{2} \mathrm{O}_{3}$ component and thus leaves behind an array of ordered $\mathrm{Mn}_{3} \mathrm{O}_{4}$ ferromagnetic spinels. Critically, we show that the shape, size, and spacing of the $\mathrm{Mn}_{3} \mathrm{O}_{4}$ nanostructures can be easily tuned by altering the oxygen environments and deposition time.

As we exploit the formation of $\mathrm{Bi}_{2} \mathrm{O}_{3}$ in oxygen-rich conditions as our primary method to create the nanocrystals, this approach is fundamentally unlike previous efforts that have used oxygen-deficient vacuum conditions to generate metal oxide nanostructures. ${ }^{27}$ Second, our end product has uniformly separated nanostructures without any matrix. This is a significant distinction from "pillar and matrix" phaseseparated nanocomposite forms that have been reported previously for complex metal oxides. ${ }^{6,28-30}$

\section{RESULTS AND DISCUSSION}

Figure $1 A, B$ illustrates this concept of phase separation and evaporation approach. The first and most important step (step 1 in Figure 1A) of this synthesis approach is to create an environment that

\author{
*Address correspondence to \\ nagarajan@unsw.edu.au. \\ Received for review May 10, 2010 \\ and accepted August 10, 2010. \\ Published online August 23, 2010. \\ $10.1021 / \mathrm{nn} 1010123$ \\ (c) 2010 American Chemical Society
}




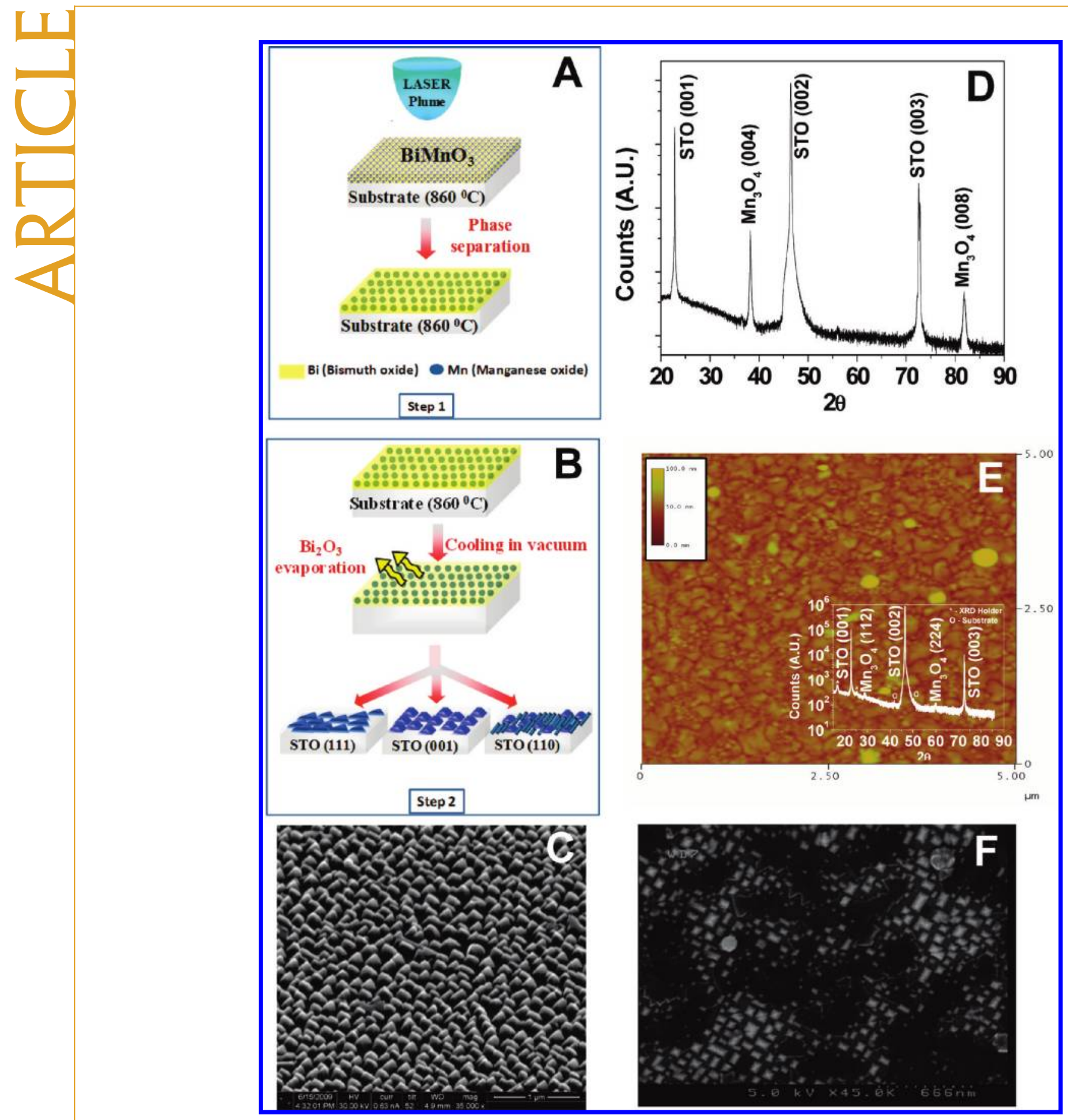

Figure 1. Synthesis technique of $\mathrm{Mn}_{3} \mathrm{O}_{4}$ nanocrystals. A schematic representation of (A) step 1: synthesis approach to create an environment that promotes perovskite instability and hence the formation of phase-separated nanostructures; (B) step 2: bismuth oxide evaporation during sample cooling and formation of $\mathrm{Mn}_{3} \mathrm{O}_{4}$ nanocrystals on (110), (001), and (111) oriented $\mathrm{SrTiO}_{3}$ substrate; (C) corresponding tilted SEM view (sample tilt $=52^{\circ}$ ) of $\mathrm{Mn}_{3} \mathrm{O}_{4}$ nanostructures grown on $(001) \mathrm{SrTiO}_{3}$ substrate; (D) $\theta-2 \theta$ XRD pattern of the sample in (C); (E) AFM topology image of a sample processed under high-vacuum conditions. The inset XRD confirms polycrystalline $\mathrm{Mn}_{3} \mathrm{O}_{4}$; (F) SEM image of the sample synthesized in phase separation conditions but quenched in full oxygen, where a number of irregularly distributed hut-shaped islands are observed. Chemical and XRD analysis of this sample confirms existence of bismuth distribution between the islands (see Supporting Information).

promotes perovskite instability via the formation of phase-separated $\mathrm{Bi}_{2} \mathrm{O}_{3}$ and manganese oxide islands. Previously reported phase diagrams $\mathrm{s}^{31,32}$ show that such conditions are typically found for oxygen-rich environments and higher temperatures. In our case, this is achieved by depositing at $860^{\circ} \mathrm{C}$ (substrate temperature) and $35 \mathrm{mTorr}$ (chamber oxygen pressure). Once the deposited film forms a phase-separated material (comprising $\mathrm{Bi}_{2} \mathrm{O}_{3}$ and manganese oxide), it is crucial to completely remove the $\mathrm{Bi}_{2} \mathrm{O}_{3}$. Now we exploit the high volatility of $\mathrm{Bi}_{2} \mathrm{O}_{3}$ (particularly under high vacuum) by cooling in high-vacuum ( $10^{-7}$ Torr), as shown in step 2 in Figure 1B. This eventually leaves behind the manganese oxide nanocrystals as confirmed by the $52^{\circ}$ 


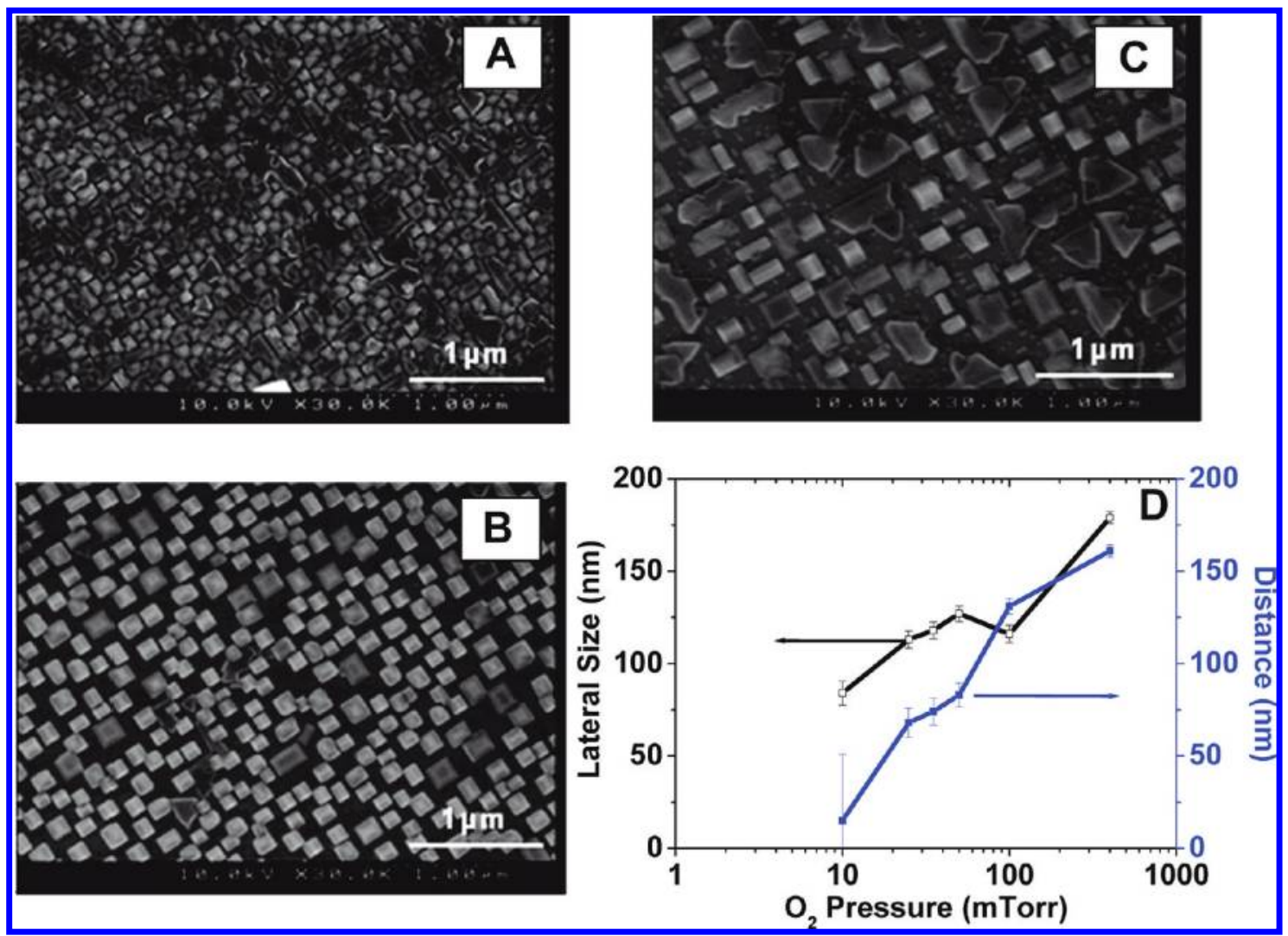

Figure 2. SEM images of the $\mathrm{Mn}_{3} \mathrm{O}_{4}$ nanostructure samples deposited on (001) oriented $\mathrm{SrTiO}_{3}$ substrate at (A) 10, (B) 35, and (C) 400 mTorr oxygen partial pressures; (D) variation in the mean lateral size and inter-nanostructure distance with chamber oxygen partial pressure.

tilted scanning electron microscopy (SEM) image shown in Figure $1 C$. The corresponding X-ray diffraction data (XRD) shown in Figure 1D reveal only (00k) peaks of the $\mathrm{Mn}_{3} \mathrm{O}_{4}$ (JCPDS 24-734) spinel phase, indicating an oriented growth of the single-crystalline nanostructures. Detailed size analysis of the tilted SEM image reveals highly populated synthesis of hut-shaped nanostructures with a rectangular base of size $\sim 125 \pm 10 \mathrm{~nm}$ and height $\sim 75 \pm 5 \mathrm{~nm}$ with an average inter-

nanostructure distance of $75 \pm 10 \mathrm{~nm}$. Lowmagnification conventional transmission electron microscope (TEM) imaging (Supporting Information Figure S1A) confirms a high density of discrete $\mathrm{Mn}_{3} \mathrm{O}_{4}$ nanostructures with the corresponding energydispersive X-ray (EDX) spectra confirming the absence of any residual $\mathrm{Bi}$ in these samples (Figure S1B).

The importance of carrying the synthesis process under the two-stage "phase separation followed by volatization" conditions is further demonstrated in Figure $1 \mathrm{E}, \mathrm{F}$. Figure $1 \mathrm{E}$ is a tapping mode atomic force microscopy (AFM) topology image of a sample that was processed fully under high-vacuum conditions. Here we find that the resultant sample is essentially a rough but continuous thin film. Although the corresponding XRD (inset) and EDX microanalysis confirms the presence of only polycrystalline $\mathrm{Mn}_{3} \mathrm{O}_{4}$ phases (i.e., Bi-containing phases were distinctly absent), Figure $1 \mathrm{E}$ shows that high vacuum alone is not sufficient to realize individual nanocrystals. This significant Bi loss under oxygendeficient processing conditions agrees with studies focused on $\mathrm{BiMnO}_{3}$ perovskite thin film synthesis. ${ }^{33} \mathrm{Next}$ we synthesized a sample where PLD was carried out in phase separation oxygen environments (35 mTorr) but then quenched under full oxygen conditions. Figure $1 \mathrm{~F}$ is a SEM image of this sample. It shows a large number of nucleated islands with pyramid or hut morphology in an irregular manner separated by flat patches. Wavedispersive spectroscopy (WDS) analysis (Supporting Information Figure S1C) of the sample confirmed a patchy distribution of bismuth in the regions between the islands, and XRD pattern of the same sample shows several weak peaks of $\mathrm{Mn}_{3} \mathrm{O}_{4}$ as well as Bi-containing phases (Supporting Information Figure S1D). Thus Figure $1 \mathrm{E}, \mathrm{F}$ collectively outlines the importance of using a two-step process in our approach.

To understand the role of oxygen environments in the synthesis of the $\mathrm{Mn}_{3} \mathrm{O}_{4}$ nanostructures, PLD synthesis was carried out for a range of chamber oxygen partial pressures (from 10 to 400 mTorr) at the same temperature and pulse conditions. Each sample was then cooled in identical vacuum conditions. Figure 2 is a panel of SEM images for some of the more significant partial pressures. The film deposited at 10 mTorr (Figure $2 \mathrm{~A}$ ) shows connected small pyramidal shaped nanostructures. On the other hand, the film deposited at 35 mTorr consisted of distinct nanostructures with nearly 


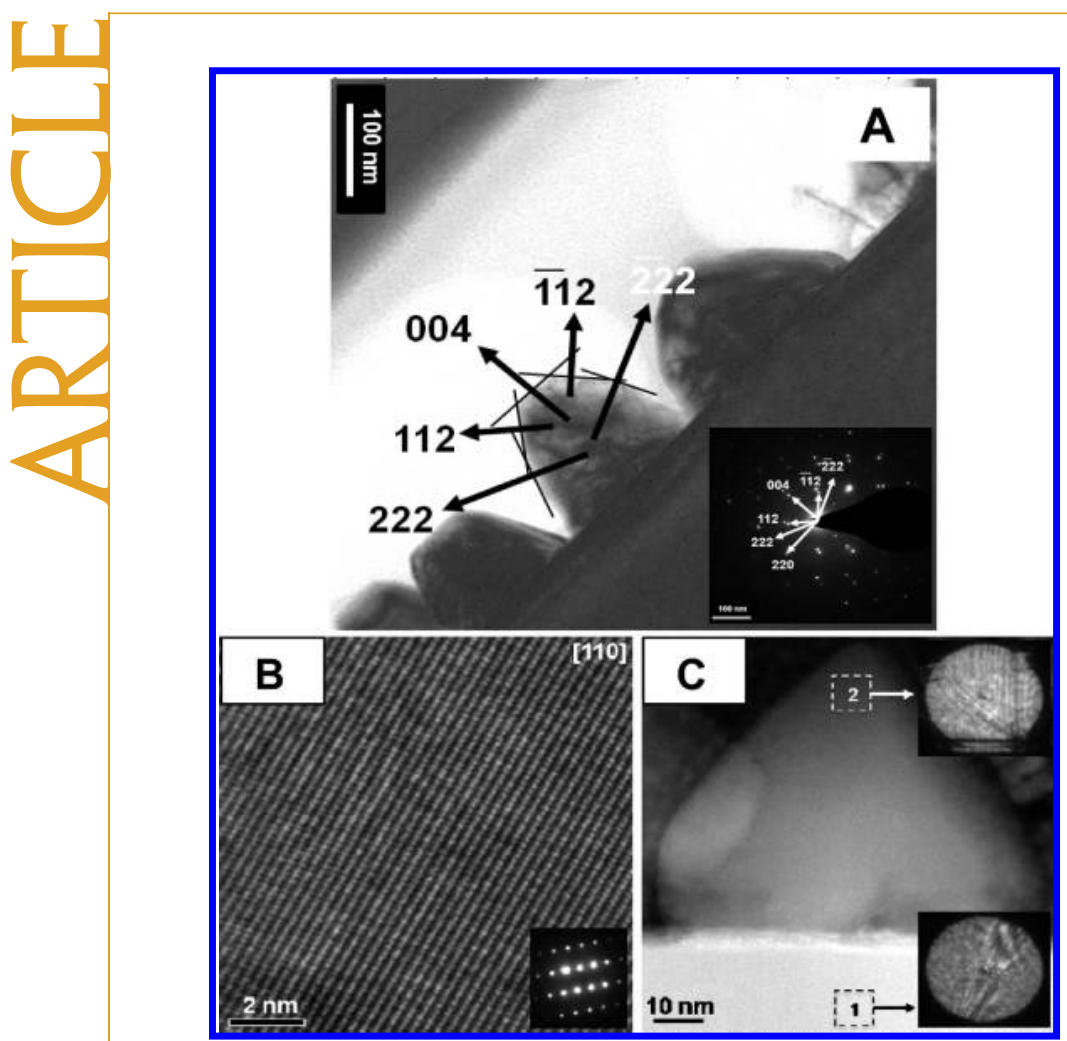

Figure 3. Structural analysis of the $\mathrm{Mn}_{3} \mathrm{O}_{4}$ nanostructures: (A) TEM imaging and selected area diffraction pattern (inset) demonstrate first that the bounding surface crystallography of the $\mathrm{Mn}_{3} \mathrm{O}_{4}$ islands is often relatively complex and second that the [100] zone axis for the $\mathrm{Sr}$ $\mathrm{TiO}_{3}$ substrate corresponds to the [110] zone axis for the $\mathrm{Mn}_{3} \mathrm{O}_{4}$; (B) high-resolution TEM (HRTEM) and (C) high-angle annular dark-field (HAADF) image, where the insets show the Kikuchi patterns for the substrate (1) and the $\mathrm{Mn}_{3} \mathrm{O}_{4}$ nanostructure (2).

square-based truncated pyramids and rectangular shaped huts, as shown in Figure 2B. Further increase in chamber oxygen partial pressure, up to 400 mTorr, leads to the formation of individual nanostructures with larger lateral size and inter-nanostructure distance, as shown in Figure $2 \mathrm{C}$.

This systematic variation in the shape evolution of the nanostructures can be understood on the basis of interaction of plume contents with the chamber oxygen along with its effects on nucleation and growth. Lower deposition pressure results in a fast-moving plume due to low probability of collision between plume contents and chamber oxygen. A high nucleation density occurs upon deposition with very little growth in nanostructure size. As the chamber oxygen pressure increases, the collision probability increases and as a consequence creates a slower plume, which allows more time for larger sized nanostructures to grow. ${ }^{34}$ Size and internanostructure distance analysis of these SEM images reveals that the mean lateral size and inter-nanostructure distance increases ( 80 to $180 \mathrm{~nm}$ and 15 to $160 \mathrm{~nm}$ ) with increasing oxygen partial pressure, from 10 to 400 mTorr (shown in Figure 2D). An analogous dependence on laser pulse frequency was also found, where increasing the pulse rate from 5 to $20 \mathrm{~Hz}$ for a fixed oxy- gen partial pressure and temperature reduced the internanocrystal distance as well as the mean lateral size.

Figure 3 illustrates TEM investigations of the $\mathrm{Mn}_{3} \mathrm{O}_{4}$ nanostructure sample deposited for 20000 laser pulses at $860^{\circ} \mathrm{C}$ in $35 \mathrm{mTorr}$ chamber oxygen pressure (Figure $1 \mathrm{C}$ ). Figure $3 \mathrm{~A}$ is a cross-section TEM image showing several $\mathrm{Mn}_{3} \mathrm{O}_{4}$ nanoislands. In combination with selected area diffraction pattern (inset) obtained from the middle nanostructure, several key points can be inferred.

First, both the image and diffraction pattern were taken with the electron beam aligned parallel to the [100] of the $\mathrm{SrTiO}_{3}$ substrate. Indexing of the diffraction spots from the $\mathrm{Mn}_{3} \mathrm{O}_{4}$ indicates that this beam direction is simultaneously parallel to the [110] zone axis for $\mathrm{Mn}_{3} \mathrm{O}_{4}$. The in-plane orientation relation must therefore be such that $[100]_{\mathrm{STO}} / /[110]_{\mathrm{Mn}_{3} \mathrm{O}^{\prime}}$ and by implication $[110]_{\mathrm{STO}} / /[100]_{\mathrm{Mn}_{3} \mathrm{O}_{4}}$. A $45^{\circ}$ misorientation of the primary lattice vectors at the interface plane should be expected as $\sqrt{ } 2 a_{\text {STO }} \approx a_{\mathrm{Mn}_{3} \mathrm{O}_{4}}$ and suggests some level of interface coherency.

Second, the nanostructures in general have relatively complex bounding surface crystallography. As can be seen, the middle nanostructure in Figure $3 \mathrm{~A}$ has seven different facets parallel to the $[1 \overline{1} 0]_{\mathrm{Mn}_{3} \mathrm{O}_{4}}$ beam direction, five of which are explicitly labeled to allow the link between the observed facets and the electron diffraction pattern to be understood (indexed to the $14_{1} /$ amd space group). Figure $3 \mathrm{~B}$ is a high-resolution TEM (HRTEM) image acquired along the [110] zone axis, showing clear lattice fringes and hence confirming the single-crystalline nature of each nanocrystal. Scanning TEM (STEM) imaging allows a fine electron probe $(\sim 1$ $\AA$ A), which can be freely positioned, to be focused onto the given specimen, and when the probe is well overfocused, Kikuchi lines are visible. ${ }^{35-37}$ Figure $3 C$ is the high-angle annular dark-field (HAADF) image of a single nanostructure and substrate, acquired under STEM mode. The inset marked as 1 displays the Kikuchi pattern from the substrate; it shows three lines intersecting with each other which is characteristic of the [110] zone axis for STO. While the inset marked as 2 displays the Kikuchi pattern from the nanostructure, it shows several lines forming a "triangular" shape, where there is more than one intersecting point. This confirms that the nanostructure has an in-plane rotation with respect to the [100] direction of the underlying substrate. Plan view examination (not shown) of several samples confirmed that the islands grow parallel to the $\langle 110\rangle$ direction of the STO substrate. Again, this can be expected on the basis of lattice mismatch arguments where $\sqrt{ } 2 a_{\mathrm{STO}} \approx a_{\mathrm{Mn}_{3} \mathrm{O}_{4}}$.

We have also investigated the dependence of the shape of the $\mathrm{Mn}_{3} \mathrm{O}_{4}$ nanocrystals on their volume by tuning the number of laser pulses during the PLD deposition. Figure 4 shows high-magnification SEM images of the nanostructure samples deposited at 2000 (Figure 4A), 5000 (Figure 4B), and 20000 (Figure 4C) laser pulses, where the other PLD parameters $\left(860^{\circ} \mathrm{C}\right.$ 


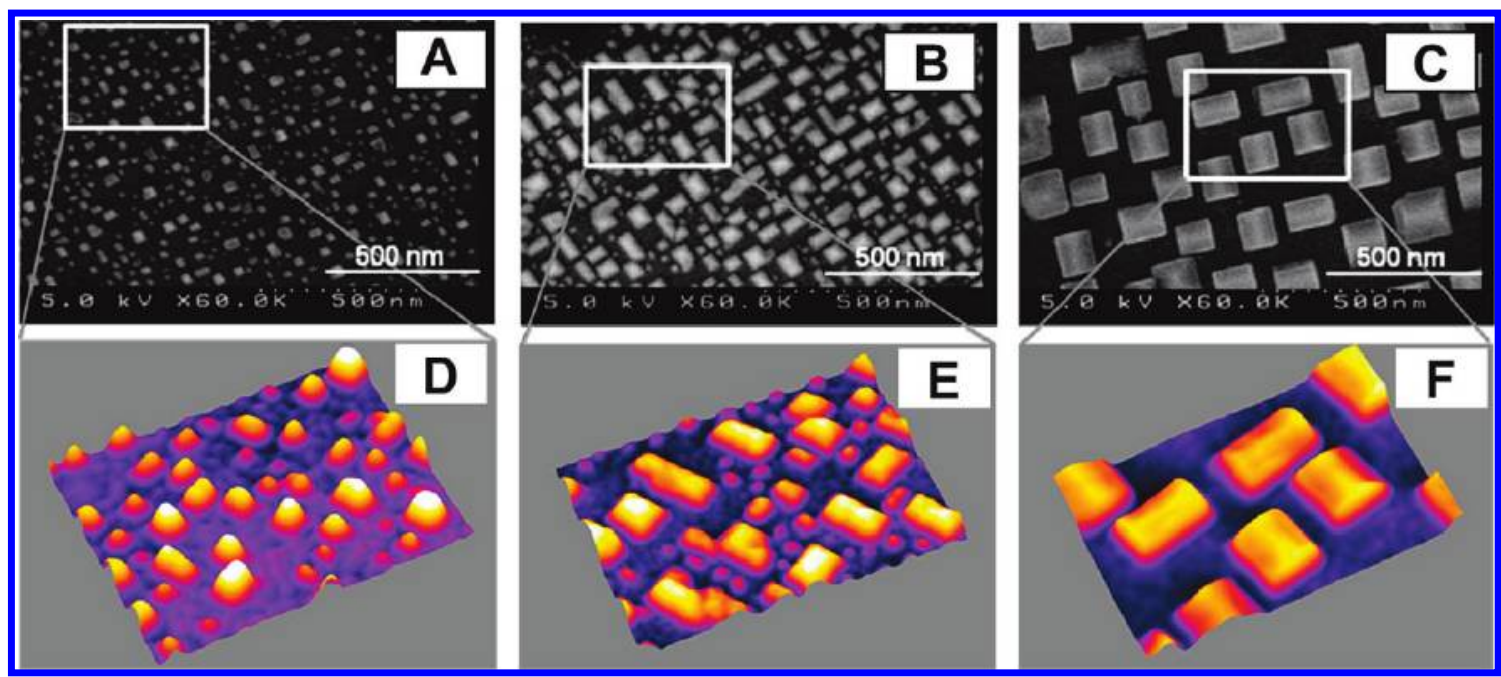

Figure 4. Morphology of the $\mathrm{Mn}_{3} \mathrm{O}_{4}$ nanostructures grown on (001) oriented $\mathrm{SrTiO}_{3}$ substrate for (A) 2000, (B) 5000, and (C) 20000 laser pulses along with their respective interactive 3D images $(D, E, F)$.

substrate temperature, $35 \mathrm{mTorr} \mathrm{O}_{2}$ pressure and cooling in vacuum) were kept identical. The SEM image shown in Figure 4A, along with its interactive 3D image generated from a smaller area of the SEM image (Figure 4D), clearly illustrates square-based pyramidal shape nanostructures growth on the substrate (also see Supporting Information Figure S2A). As the deposition proceeds to 5000 laser pulses \{Figure 4B\}, one observes the islands beginning to coalesce into larger sized nanostructures. Second, a clear shape transition from pyramids to hut-shaped nanocrystals begins to occur. This shape transition process via nanostructure aggregation can easily be resolved in Figure 4E (and Figure S2). Furthermore, at 20000 laser pulses, almost $99 \%$ of the nanostructures have shape of the roof of a hut, as shown in Figure 4C,F and Figure S2C.
Further shape control of the $\mathrm{Mn}_{3} \mathrm{O}_{4}$ nanocrystals can be achieved by exploiting their epitaxial relationship with the STO substrate. STO has a lattice parameter $a=b=c=3.905 \AA$. $\mathrm{Mn}_{3} \mathrm{O}_{4}$ has lattice parameters of $a=b=5.77 \AA$ and $c=9.44 \AA$. For a STO (001) substrate, this results in $\mathrm{Mn}_{3} \mathrm{O}_{4}$ nanocrystals having an (001) interface with an in-plane rotation of $45^{\circ}$ and results in a $4 \%$ compressive lattice mismatch. Therefore, if $\mathrm{Mn}_{3} \mathrm{O}_{4}$ nanocrystals are nucleated on STO (111) or STO (110) substrates, in order to minimize the interfacial energy, one would expect them to be oriented along [111] and [110] directions. This results in dramatically different shapes for the nanocrystals, as demonstrated in Figure 5, which shows SEM images along with their XRD data of $\mathrm{Mn}_{3} \mathrm{O}_{4}$ nanostructures fabricated using (001), (111), and (110) oriented $\mathrm{SrTiO}_{3}$ substrates.
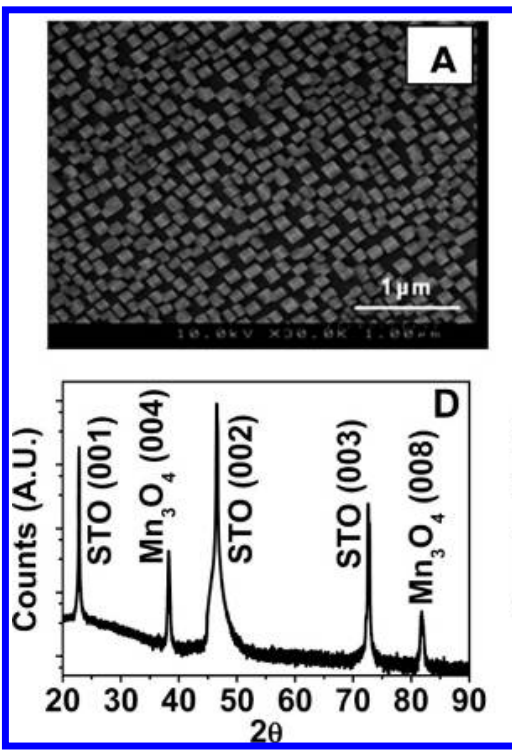
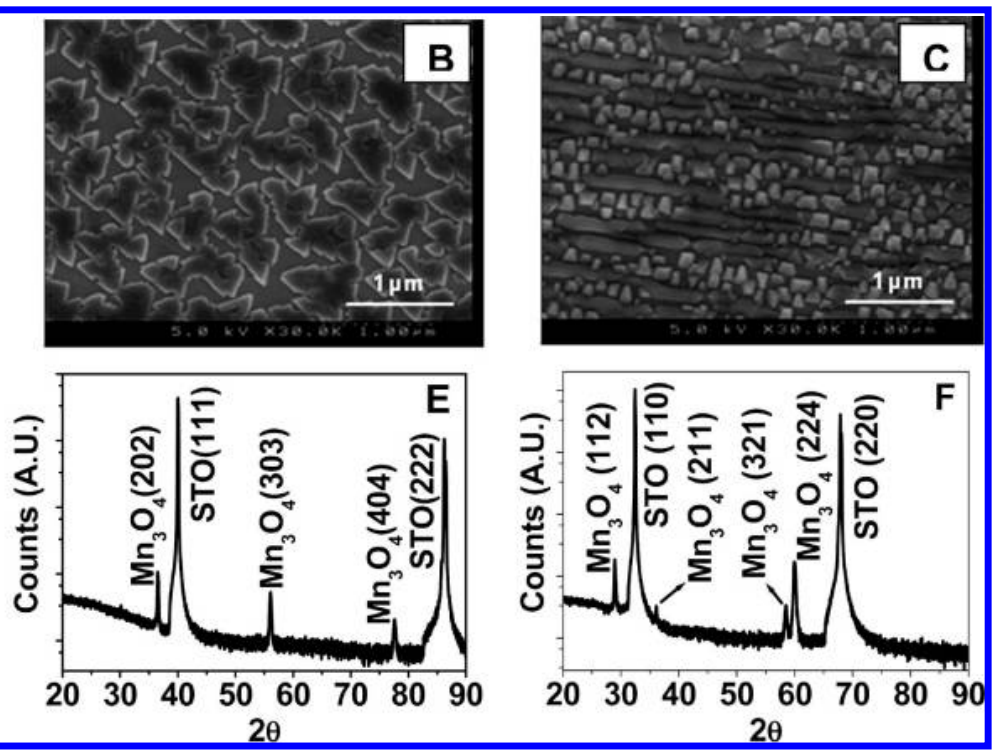

Figure 5. SEM images and respective XRD patterns for $\mathrm{Mn}_{3} \mathrm{O}_{4}$ nanostructures grown on $(A, D)(001),(B, E)(111)$, and $(C, F)$ (110) oriented $\mathrm{SrTiO}_{3}$ substrates. These samples were deposited at substrate temperature of $860{ }^{\circ} \mathrm{C}$, oxygen partial pressure of $35 \mathrm{mTorr}$, pulse repetition rate of $5 \mathrm{~Hz}$, and 20000 laser pulses. 


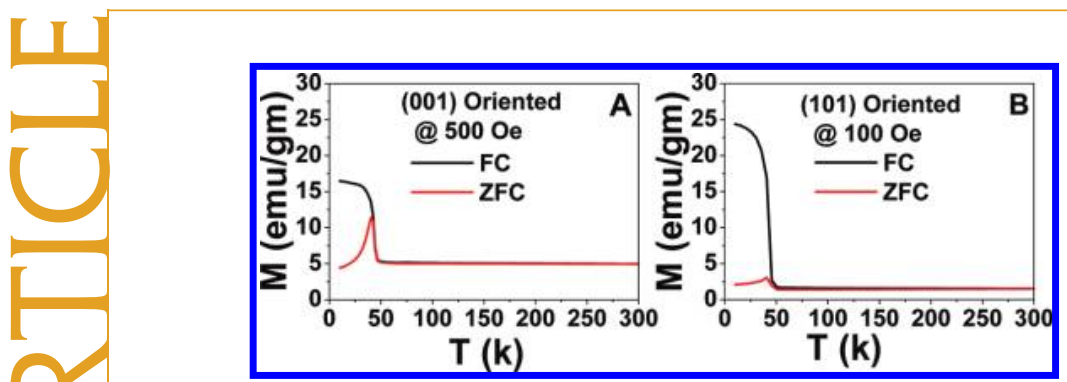

Figure 6. Temperature-dependent magnetization at (A) 500 Oe for (001) oriented and (B) 100 Oe for (101) oriented $\mathrm{Mn}_{3} \mathrm{O}_{4}$ nanostructures grown on (001) oriented $\mathrm{SrTiO}_{3}$ at $860^{\circ} \mathrm{C}$ in $35 \mathrm{mTorr}$ oxygen for 20000 laser pulses. They were measured at 500 and 100 Oe applied magnetic field. $\mathrm{Mn}_{3} \mathrm{O}_{4}$ nanostructure shows ferrimagnetic behavior at low temperature. For bulk $\mathrm{Mn}_{3} \mathrm{O}_{4}$ hausmannite, Curie temperature is about $42 \mathrm{~K}$, where as in our case for (001) and (101) oriented $\mathrm{Mn}_{3} \mathrm{O}_{4}$ sample, $T_{\mathrm{c}}$ was found at 40 and $42 \mathrm{~K}$.

As it has been discussed previously for the (001) oriented $\mathrm{SrTiO}_{3}$ substrate, isolated $\mathrm{Mn}_{3} \mathrm{O}_{4}$ nanostructures having a hut shape are formed. The corresponding XRD data shown in Figure 5D for nanostructure grown on (001) oriented $\mathrm{SrTiO}_{3}$ substrate reveal only (00k) peaks, indicating an epitaxial growth of the single-crystalline nanostructures. Conversely, the shape of the nanostructure grown on (111) oriented $\mathrm{SrTiO}_{3}$ substrate is entirely different. More or less flat and interconnected triangular platelet-shaped nanostructures are observed (see Figure 5B), and its XRD data (see Figure 5E) indicate that these nanostructures are (101) oriented, which is the natural direction of growth of hausmannite. ${ }^{38} \mathrm{On}$ the other hand, the $\mathrm{Mn}_{3} \mathrm{O}_{4}$ nanostructures grown on (110) $\mathrm{SrTiO}_{3}$ substrate have a mixture of different shapes (see Figure $5 \mathrm{C}$ and its XRD data). Figure $5 \mathrm{~F}$ indicates that these are of multiple orientations in nature.

The observations above, namely, that $\mathrm{Mn}_{3} \mathrm{O}_{4}$ nanocrystal shape is influenced both by volume and substrate orientation, raises the tantalizing prospect of tuning the nanocrystal shapes to optimize their properties for particular applications. In general, the equilibrium shape of a supported crystallite can be determined using Winterbottom's construction, ${ }^{39}$ also known as the Wulff-Kaichew theorem. The equilibrium crystal shape is determined by considering the surface energies of the crystallite facets, the interface energy between the crystallite and the substrate, and the surface energy of the substrate. What this theorem does not include are factors relating to interface strain or the effect of metastable shapes and orientations. For example, if lattice mismatch strain is not relieved via misfit dislocations, then the strain energy in the nanocrystals will grow disproportionately to their volume. This will result in shape changes as the nanocrystals grow, as observed in this study for the [001] oriented $\mathrm{Mn}_{3} \mathrm{O}_{4}$ nanocrystals and commonly seen in semiconductor epitaxy ${ }^{40}$ Furthermore, if there is a particularly favorable epitaxial rela- tionship between the supported crystal and the substrate, then the crystal orientation can be determined in the early nucleation stages giving rise to a metastable shape. This may be occurring for the STO (110) oriented substrates shown here.

Of note also is the strong temperature dependence of the ultimate nanostructure shape in this process. The exponential dependence of vapor pressure on temperature would imply that even a slight change in temperature should have strong change in the evaporation of the bismuth oxide phases. While all data discussed in this paper are for fixed synthesis temperature, we indeed have found that slightly decreasing or increasing the growth temperature $\left(\sim 10^{\circ} \mathrm{C}\right)$ results in dramatically altered nanostructure shape (unpublished). Further in situ investigations are currently being performed to understand this.

Finally, we explore the functional behavior of these nanostructures. Temperature-dependent magnetization data for (001) oriented and (101) oriented $\mathrm{Mn}_{3} \mathrm{O}_{4}$ nanostructures grown on (001) oriented $\mathrm{SrTiO}_{3}$ at 860 ${ }^{\circ} \mathrm{C}$ were acquired using a Quantum Design MPMS-XL. The measurements were done in 500 and $100 \mathrm{Oe}$ applied magnetic fields, respectively. As shown in the Figure 6, $\mathrm{Mn}_{3} \mathrm{O}_{4}$ nanostructure shows ferrimagnetic behavior at low temperatures, where the $T_{\mathrm{c}}$ for the (001) and (101) oriented $\mathrm{Mn}_{3} \mathrm{O}_{4}$ samples was found at 40 and $42 \mathrm{~K}$. In comparison, it has been reported that bulk $\mathrm{Mn}_{3} \mathrm{O}_{4}$ hausmannite has a Curie temperature of $\sim 42 \mathrm{~K}^{38}$

\section{CONCLUSION}

To conclude, we present a template-free facile approach for the synthesis of $\mathrm{Mn}_{3} \mathrm{O}_{4}$ metal oxide nanocrystals using $\mathrm{BiMnO}_{3}$ perovskite precursors, employing the concept of perovskite instability and phase separation followed by bismuth oxide evaporation. Distinct variations in the morphologies, size, and spacing were observed. These could also be easily tuned by the processing conditions. Nanocrystal shape control is a particularly active field in materials research because of the shape/property relationships that can be exploited. The $\mathrm{Mn}_{3} \mathrm{O}_{4}$ nanocrystal on STO substrate system appears to be an excellent candidate for this type of study. As our process primarily hinges on the phase separation and subsequent volatization of $\mathrm{Bi}_{2} \mathrm{O}_{3}$, it can be extended to any other Bi-containing complex metal oxide system. We have carried out similar pilot experiments on the creation of technologically important magnetite $\left(\mathrm{Fe}_{3} \mathrm{O}_{4}\right)$ and titania $\left(\mathrm{TiO}_{2}\right)$ nanostructures (see Supporting Information). These studies demonstrate the applicability of the phase separation synthesis method over a broad range of oxides.

\section{METHODS}

Nanostructures used in this study were grown on vicinal single-crystalline (001) $\mathrm{SrTiO}_{3}$ substrates procured from SHINKO-
SHA Japan. A bulk BiMnO ${ }_{3}$ ceramic target was used as precursor. Nanostructures were grown using pulsed laser deposition (PLD) with a $\operatorname{KrF}(\lambda=248 \mathrm{~nm}$ ) excimer laser at a laser density of 
$\sim 2 \mathrm{~J} \mathrm{~cm}^{-2}$. The effects of substrate temperature (in the range from 800 to $900^{\circ} \mathrm{C}$ ), chamber oxygen partial pressure (in the range from 2 to $400 \mathrm{mTorr}$ ), and deposition rate ( 0.1 to $2 \mathrm{~nm}$ $\mathrm{min}^{-1}$ ) were also investigated. To ensure repeatability, each growth run was repeated three times using identical conditions. Nanostructures were characterized using a Hitachi S4500 field emission scanning electron microscope (FESEM) with a resolution of $\sim 2 \mathrm{~nm}$. Elemental analysis was carried out on the Hitachi with an Oxford Isis energy-dispersive X-ray analyzer. A Philips X'pert MRD thin film X-ray diffractometer was used for XRD spectra. Cross-sectional TEM samples were prepared by both standard tripod polishing and ion milling techniques, ${ }^{35}$ as well as focused ion beam milling on an FEI200TEM FIB microscope. HRTEM studies were performed using a JEOL FEGTEM operated at $300 \mathrm{kV}$ and a FEI Tecnai F20 FEGTEM operated at $200 \mathrm{kV}$, while HAADF studies were performed using a double-corrected Titan $\mathrm{S}$-Twin microscope operated at $300 \mathrm{kV}$. Temperature-dependent magnetization was measured by MPMS-XL of Quantum Design. The magnetic fields for both measurements were applied along the in-plane direction with respect to the substrates.

Acknowledgment. The research at UNSW was supported in part by an Australia-India DIISR and ARC Discovery and LIEF Grant. Y.H.C. also acknowledges the support of the National Science Council, ROC, under Contract NSC 98-2119-M-009-016.

Supporting Information Available: Additional experimental details and figures. This material is available free of charge via the Internet at http://pubs.acs.org.

\section{REFERENCES AND NOTES}

1. Yu, S.-H.; Yoshimura, M. Direct Fabrication of Ferrite $\mathrm{MFe}_{2} \mathrm{O}_{4}(\mathrm{M}=\mathrm{Zn}, \mathrm{Mg}) / \mathrm{Fe}$ Composite Thin Films by Soft Solution Processing. Chem. Mater. 2000, 12, 3805-3810.

2. Jana, N. R.; Chen, Y.; Peng, X. Size- and Shape-Controlled Magnetic ( $\mathrm{Cr}, \mathrm{Mn}, \mathrm{Fe}, \mathrm{Co}, \mathrm{Ni})$ Oxide Nanocrystals via a Simple and General Approach. Chem. Mater. 2004, 16, 3931-3935.

3. Bao, N. Z.; Shen, L. M.; An, W.; Padhan, P.; Turner, C. H.; Gupta, A. Formation Mechanism and Shape Control of Monodisperse Magnetic $\mathrm{CoFe}_{2} \mathrm{O}_{4}$ Nanocrystals. Chem. Mater. 2009, 21, 3458-3468.

4. Kim, D.; Lee, N.; Park, M.; Kim, B. H.; An, K.; Hyeon, T. Synthesis of Uniform Ferrimagnetic Magnetite Nanocubes. J. Am. Chem. Soc. 2009, 131, 454-455.

5. Gibert, M.; Puig, T.; Obradors, X.; Benedetti, A.; Sandiumenge, F.; Huhne, R. Self-Organization of Heteroepitaxial $\mathrm{CeO}_{2}$ Nanodots Grown from Chemical Solutions. Adv. Mater. 2007, 19, 3937-3942.

6. Ruzmetov, D.; Seo, Y.; Belenky, L. J.; Kim, D. M.; Ke, X. L.; Sun, H. P.; Chandrasekhar, V.; Eom, C. B.; Rzchowski, M. S. Pan, X. Q. Epitaxial Magnetic Perovskite Nanostructures. Adv. Mater. 2005, 17, 2869-2872.

7. Service, R. F. Materials Science: Small Clusters Hit the Big Time. Science 1996, 271, 920-922.

8. Puntes, V. F.; Krishnan, K. M.; Alivisatos, A. P. Colloidal Nanocrystal Shape and Size Control: The Case of Cobalt. Science 2001, 291, 2115-2117.

9. Park, J.; An, K. J.; Hwang, Y. S.; Park, J. G.; Noh, H. J.; Kim, J. Y.; Park, J. H.; Hwang, N. M.; Hyeon, T. Ultra-Large-Scale Syntheses of Monodisperse Nanocrystals. Nat. Mater. 2004, 3, 891-895.

10. Yin, Y.; Alivisatos, A. P. Colloidal Nanocrystal Synthesis and the Organic-Inorganic Interface. Nature 2005, 437, 664670.

11. Park, J.; Joo, J.; Kwon, Soon, G.; Jang, Y.; Hyeon, T. Synthesis of Monodisperse Spherical Nanocrystals. Angew. Chem. Int. Ed. 2007, 46, 4630-4660.

12. Brus, L. Electronic Wave Functions in Semiconductor Clusters: Experiment and Theory. J. Phys. Chem. 1986, 90, 2555-2560.

13. Goldstein, A. N.; Echer, C. M.; Alivisatos, A. P. Melting in Semiconductor Nanocrystals. Science 1992, 256, $1425-1427$.
14. Alivisatos, A. P. Semiconductor Clusters, Nanocrystals, and Quantum Dots. Science 1996, 271, 933-937.

15. El-Sayed, M. A. Small is Different: Shape-, Size-, and Composition-Dependent Properties of Some Colloidal Semiconductor Nanocrystals. Acc. Chem. Res. 2004, 37, 326-333.

16. Macak, J. M.; Zollfrank, C.; Rodriguez, B. J.; Tsuchiya, H.; Alexe, M.; Creil, P.; Schmuki, P. Ordered Ferroelectric Lead Titanate Nanocellular Structure by Conversion of Anodic $\mathrm{TiO}_{2}$ Nanotubes. Adv. Mater. 2009, 21, 3121-3125.

17. Wang, N.; Guo, L.; He, L.; Cao, X.; Chen, C. P.; Wang, R. M.; Yang, S. H. Facile Synthesis of Monodisperse $\mathrm{Mn}_{3} \mathrm{O}_{4}$ Tetragonal Nanoparticles and Their Large-Scale Assembly into Highly Regular Walls by a Simple Solution Route. Small 2007, 3, 606-610.

18. Hu, C. C.; Wu, Y. T.; Chang, K. H. Low-Temperature Hydrothermal Synthesis of $\mathrm{Mn}_{3} \mathrm{O}_{4}$ and $\mathrm{MnOOH}$ Single Crystals: Determinant Influence of Oxidants. Chem. Mater. 2008, 20, 2890-2894.

19. Zhao, N.; Nie, W.; Liu, X.; Tian, S.; Zhang, Y.; Ji, X. Shapeand Size-Controlled Synthesis and Dependent Magnetic Properties of Nearly Monodisperse $\mathrm{Mn}_{3} \mathrm{O}_{4}$ Nanocrystals. Small 2008, 4, 77-81.

20. Yu, T.; Moon, J.; Park, J.; Park, Y. I.; Na, H. B.; Kim, B. H.; Song, I. C.; Moon, W. K.; Hyeon, T. Various-Shaped Uniform $\mathrm{Mn}_{3} \mathrm{O}_{4}$ Nanocrystals Synthesized at Low Temperature in Air Atmosphere. Chem. Mater. 2009, 21, 2272-2279.

21. Sakai, N.; Ebina, Y.; Takada, K.; Sasaki, T. Electrochromic Films Composed of $\mathrm{MnO}_{2}$ Nanosheets with Controlled Optical Density and High Coloration Efficiency. J. Electrochem. Soc. 2005, 152, E384-E389.

22. Bruchez, M., Jr.; Moronne, M.; Gin, P.; Weiss, S.; Alivisatos, A. P. Semiconductor Nanocrystals as Fluorescent Biological Labels. Science 1998, 281, 2013-2016.

23. Einaga, H.; Futamura, S. Catalytic Oxidation of Benzene with Ozone Over Alumina-Supported Manganese Oxides. J. Catal. 2004, 227, 304-312.

24. Weissleder, R.; Kelly, K.; Sun, E. Y.; Shtatland, T.; Josephson, L. Cell-Specific Targeting of Nanoparticles by Multivalent Attachment of Small Molecules. Nat. Biotechnol. 2005, 23, 1418-1423.

25. Yamashita, T.; Vannice, $\mathrm{A} . \mathrm{N}_{2} \mathrm{O}$ Decomposition over Manganese Oxides. J. Catal. 1996, 161, 254-262.

26. Yamashita, T.; Vannice, A. NO Decomposition over $\mathrm{Mn}_{2} \mathrm{O}_{3}$ and $\mathrm{Mn}_{3} \mathrm{O}_{4}$. J. Catal. 1996, 163, 158-168.

27. Mohaddes-Ardabili, L.; Zheng, H.; Ogale, S. B.; Hannoyer, B.; Tian, W.; Wang, J.; Lofland, S. E.; Shinde, S. R.; Zhao, T.; Jia, Y.; et al. Self-Assembled Single-Crystal Ferromagnetic Iron Nanowires Formed by Decomposition. Nat. Mater. 2004, 3, 533-538.

28. Zheng, H.; Straub, F.; Zhan, Q.; Yang, P.-L.; Hsieh, W.-K.; Zavaliche, F.; Chu, Y.-H.; Dahmen, U.; Ramesh, R. SelfAssembled Growth of $\mathrm{BiFeO}_{3}-\mathrm{CoFe}_{2} \mathrm{O}_{4}$ Nanostructures. Adv. Mater. 2006, 18, 2747-2752.

29. MaCmanus-Driscoll, J. L.; Zerrer, P.; Wang, H. Y.; Yang, H.; Yoon, J.; Fouchet, A.; Yu, R.; Blamire, M. G.; Jia, Q. X. Strain Control and Spontaneous Phase Ordering in Vertical Nanocomposite Heteroepitaxial Thin Films. Nat. Mater. 2008, 7, 314-320.

30. Yang, H.; Wang, H. Y.; Yoon, J.; Wang, Y. Q.; Jain, M.; Feldmann, D. M.; Dowden, P. C.; MacManus-Driscoll, J. L.; Jia, Q. X. Vertical Interface Effect on the Physical Properties of Self-Assembled Nanocomposite Epitaxial Films. $\underline{A d v}$. Mater. 2009, 21, 3794-3798.

31. Bea, H.; Bibes, M.; Barthelemy, A.; Bouzehouane, K.; Jacquet, E.; Khodan, A.; Contour, J.-P.; Fusil, S.; Wyczisk, F.; Forget, A.; et al. Influence of Parasitic Phases on the Properties of $\mathrm{BiFeO}_{3}$ Epitaxial Thin Films. Appl. Phys. Lett. 2005, 87, 072508-p1-072508-p3.

32. Anbusathaiah, V.; Cheng, C. J.; Lim, S. H.; Murakami, M.; Salamanca-Riba, L. G.; Takeuchi, I.; Nagarajan, V. Role of Oxygen Partial Pressure and Seed Layer Chemistry in Flux Mediated Epitaxy of Single Phase Multiferroic $\mathrm{BiFeO}_{3}$ Thin Films. Appl. Phys. Lett. 2008, 93, 192906-p1-192906-p3. 

C.; Sánchez, F.; Fontcuberta, J. Thin Films in Ternary $\mathrm{Bi}-\mathrm{Mn}-\mathrm{O}$ System Obtained by Pulsed Laser Deposition. Mater. Sci. Enq.: B 2007, 144, 138-142.

34. Campbell, A. L.; Biggers, R. R.; Subramanyam, G.; Kozlowski, G.; Kleismit, R. A.; Zate, H. N.; Hopkins, S. C.; Glowacki, B. A.; Riehl, B. D.; Peterson, T. L. Microwave Characterization of Nanostructured Ferroelectric $\mathrm{Ba}_{0.6} \mathrm{Sr}_{0.4} \mathrm{TiO}_{3}$ Thin Films Fabricated by Pulsed Laser Deposition. Nanotechnology 2008, 19, 485704-p1-485704p14.

35. Williams, D. B.; Carter, C. B. Transmission Electron Microscopy; Plenum Press: New York, 1996; pp 729-733.

36. Browning, N. D.; Wallis, D. J.; Nellist, P. D.; Pennycook, S. J. EELS in the STEM: Determination of Materials Properties on the Atomic Scale. Micron 1997, 28, 333-348.

37. Browning, N. D.; Arslan, I.; Moeck, P.; Topuria, T. Atomic Resolution Scanning Transmission Electron Microscopy. Phys. Status Solidi B 2001, 227, 229-245.

38. Wang, Z. H.; Geng, D. Y.; Zhang, Y. J.; Zhang, Z. D. Morphology, Structure and Magnetic Properties of SingleCrystal $\mathrm{Mn}_{3} \mathrm{O}_{4}$ Nanorods. J. Cryst. Grow. 2008, 310, 4148-4151.

39. Winterbottom, W. L. Equilibrium Shape of a Small Particle in Contact with a Foreign Substrate. Acta Mater. 1967, 15, 303-310.

40. Medeiros-Ribeiro, G.; Bratkovski, A. M.; Kamins, T. I.; Ohlberg, D. A. A.; Williams, R. S. Shape Transition of Germanium Nanocrystals on a Silicon (001) Surface from Pyramids to Domes. Science 1998, 279, 353-355. 